\section{BOOK REVIEW}

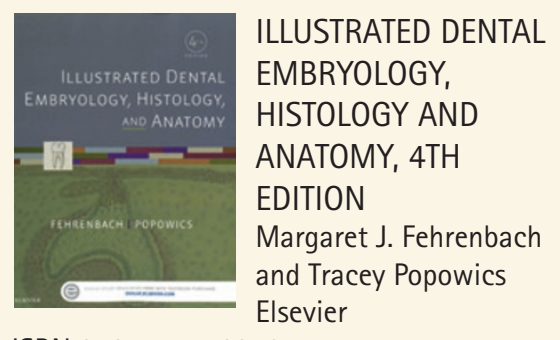

ISBN 9781455776856

Illustrated dental embryology, histology and anatomy, presents each topic in a stand-alone unit. This format enables the textbook's core subjects to be read independently or collectively, as required. The book is accessible with numerous diagrams and photographs on each page. Key terms are highlighted and subject areas cross-referenced, enabling topics to be easily located. The beginning of each section contains learning objectives, which provides the reader with an indication of what will be covered.

The book begins with an introduction to oral structures and head and neck anatomy, providing clear descriptions and definitions of key terms. It then covers oral and head and neck embryology, from conception to birth, with the inclusion of some growth disorders. Detailed diagrams and flow charts help illustrate the information covered, and aid understanding of the text. Tooth eruption and morphology is explained meticulously, with the addition of numerous photographs, tables and diagrams. While the information provided in this section is dense, it is still easily digestible and almost as good as examining a real tooth. The book then covers histology of the oral tissues with some integrated basic pathology, and finally gives a brief introduction to dental anatomy. The 4th edition also includes up to date evidence on enamel formation, dental biofilms, occlusion and smile designs. Although written by American authors, the book uses UK terminology.

Fehrenbach and Popowics provide a comprehensive guide to dental science and this book is a great investment for students revising for exams or those looking to review these topics. It should be noted, however, that the integration of pathology into this textbook is quite limited. While more in-depth information may be found in a specialised textbook for each topic, you will be hard pushed to find such a clear and user-friendly read. Not to mention that it's four books in one, which makes it great value.

L. Horsfall

\title{
A NEW WRITER ON THE INAUGURAL NEW WRITER'S WORKSHOP
}

Organised by the British Dental Editors Forum (BDEF), the first New Writer's Workshop took place on 8 September 2015 at the British Dental Association. Clinicians from around the UK attended the event, and we asked attendee and award winner Nikki Patel to give us her insight on what went on throughout the day.

The BDEF's primary aims are to ensure high quality and ethical dental publications and to enhance communication within dentistry. Past BDEF President Professor Nairn Wilson has described the Forum's aims and aspirations as 'providing support for dental editors and encouraging quality and confidence in dental publications'.

The workshop provided a platform to build new connections and enabled delegates to gain a better insight into the opportunities available in the less renowned world of dental publishing.

The day commenced with a presentation from Stephen Hancocks OBE (Editor-in-Chief $B D J$ ) and Ruth Doherty (Managing Editor $B D J$ ), on how to get papers published, with Professor Kenneth Eaton, BDEF Chair, lending us his considerable knowledge on what editors look for in papers and the peer review process. In the afternoon, we were given the opportunity to sharpen our skills on critically appraising research, creating effective social media posts and campaigns before finishing up with a talk from Professor Wilson on the pitfalls of plagarism.

I felt the enthusiasm and passion of the speakers for publishing really shone through during the course of the day, which seemed to transfer to all attendees, leaving me feeling greatly inspired.

Attending this day has given me the encouragement and confidence to continue writing and it has helped me to gain the knowledge to continue my path towards writing articles of a high quality. Additionally, it has given me the opportunity to broaden my horizons in my career and lead it in a direction less well travelled in dentistry.

This first workshop of its kind proved to be a great success and subsequently it has been planned to make this an annual event.
Later in the evening, the foyer of the BDA was transformed into a reception with canapés and drinks, ready for the presentations of the BDEF/BDIA Young Dental Communicator of the Year Awards 2015. The Award acknowledges the accomplishments and future potential of young dental writers and communicators.

I feel truly honoured that my article on community dentistry, which appeared in the $B D J$, was selected for the first prize. I am passionate about the area of dentistry I work within and for my article to be recognised for its merits is an accomplishment for the whole field of community dentistry.

If you are interested in writing I would encourage you to do so. All writers under the age of 35 living in the UK at the time their communication was published can be nominated. Look out for the workshop next year and beyond. It really does give you fantastic insight into a very competitive field.

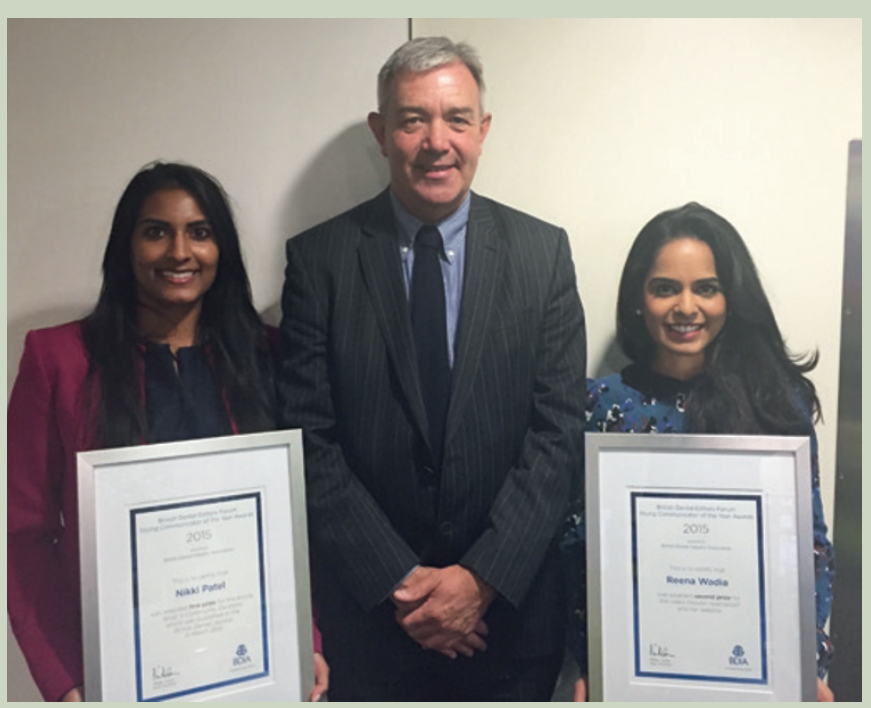

Stephen Hancocks with Nikki Patel (left) and Reena Wadia (right), winners at the Young Dental Communicator of the Year Awards. 